\title{
Detection of coronary artery disease in diabetic patients
}

\author{
C. Paillole ${ }^{1}$, J. Ruiz ${ }^{2}$, J.M.Juliard ${ }^{1}$, H. Leblanc ${ }^{2}$, R. Gourgon ${ }^{1}$, Ph. Passa ${ }^{2}$ \\ ${ }^{1}$ Department of Cardiology, Bichat Hospital, Paris, France \\ ${ }^{2}$ Department of Diabetology, Saint Louis Hospital, Paris, France
}

Summary Coronary artery disease may be difficult to detect in diabetic patients. This study was designed to determine the specificity and sensitivity of three noninvasive tests. Accordingly, the results of 48-h ambulatory electrocardiogram (ECG) monitoring, maximal ECG exercise test, and intravenous dipyridamole myocardial thallium scintigraphy were compared in 59 middle-aged diabetic patients who were consecutively selected for suspected coronary artery disease. All patients also underwent coronary angiography, which was performed regardless of the results of the non-invasive tests. Twenty patients $(34 \%)$ had significant coronary lesions, i.e. stenosis equal to or greater than $70 \%$, and 16 of these 20 patients $(80 \%)$ had double or triple vessel disease. Sensitivity and specificity were, respectively, $25 \%$ and
$88 \%$ for ambulatory ECG monitoring, $75 \%$ and $77 \%$ for the exercise test and $80 \%$ and $87 \%$ for thallium myocardial scintigraphy. This observation strongly supports the use of non-invasive tests for the detection of coronary artery disease in those diabetic patients at high risk of such disease. As the exercise test is cheaper and more widely available than thallium myocardial scintigraphy it should be used as a first line examination. Dipyridamole myocardial scintigraphy may provide an alternative solution for those patients who cannot perform maximal exercise, or with atypical clinical presentation. [Diabetologia (1995) 38: 726-731]

Key words Non-invasive test, detection, coronary artery disease, diabetic patients.
Large epidemiological prospective studies have shown that coronary artery disease (CAD) is the main cause of morbidity and death in patients with diabetes mellitus [1-3]. Recently, the Multiple Risk Factor Intervention Trial (MRFIT) [4] reported that the mortality rate for CAD and cardiovascular disease was three times higher in diabetic men than in non-diabetic men. Furthermore, a significant independent association between diabetes and cardiovascular mortality was definitively demonstrated in this trial.

Received: 17 June 1994 and in revised form: 19 December 1994

Corresponding author: Professor Ph.Passa, Hôpital Saint Louis, 1 avenue Claude Vellefaux, F-75010 Paris, France Abbreviations: ECG, Electrocardiogram; CAD, coronary artery disease; IDDM, insulin-dependent diabetes mellitus; NIDDM, non-insulin-dependent diabetes mellitus.
In diabetic populations, the symptoms and clinical course of CAD often diverge from the familiar form [5]. Thus, it has repeatedly been suggested that silent myocardial ischaemia, which has a poor prognosis and sometimes reveals the presence of severe CAD, is more frequent among these populations [6-12].

In spite of the alarming epidemiological results and the atypical CAD presentation, early and intensive detection of CAD in diabetic populations remains inadequate and is not part of the routine care. In diabetic patients, the sensitivity and specificity of the non-invasive tests for detection of CAD are poorly known. Only a few studies have included subjects undergoing coronary angiography and concerned special groups of diabetic patients [13].

The aim of this prospective study was, to our knowledge for the first time, to test prospectively the efficacy of three non-invasive tests commonly used for diagnosis of CAD. The diabetic patients included 
were suspected of having CAD, which, from the ethical point of view, justified performing coronary angiography. However, patients were selected from a diabetic clinic population, and no accurate pre-test of probability of CAD was performed.

All the patients who were selected underwent successive 48-h ambulatory electrocardiogram (ECG), bicycle exercise ECG testing, intravenous dipyridamole thallium 201 myocardial tomo-scintigraphy and coronary angiography. The sensitivity, specificity and predictive values of each non-invasive test were then calculated.

\section{Patients and methods}

Patients. Diabetic patients were consecutively recruited from January 1991 to March 1992 in the Department of Diabetology at the Saint-Louis Hospital in Paris, a tertiary referral centre. They all gave written informed consent to participate in the study, which was approved by the Ethics Committee of the Centre Hospitalo-Universitaire Lariboisière, Saint Louis.

Patients were males or females with insulin-dependent diabetes mellitus (IDDM) or non-insulin-dependent diabetes (NIDDM), aged between 40 and 70 years. They were suspected of having CAD because they complained of either typical angina as defined by Braunwald [14] or atypical angina i.e. brief (less than 2-min duration) or prolonged (more than 15 min), rest constricting angina, exercise dyspnoea or because they exhibited resting ECG abnormalities including abnormal ST-T segment. In some cases, these ECG abnormalities were associated with clinical manifestations.

We excluded patients with previous myocardial infarction, and ECG resting $Q$ wave abnormalities, unstable angina, left bundle branch block or valvular heart disease, clinical diabetic neuropathy, and severe renal insufficiency (creatinine clearance of less than $45 \mathrm{ml} / \mathrm{min}$ ). Patients with asthma were also excluded as this condition is a contra-indication for dipyridamole myocardial scintigraphy.

Five patients who fulfilled the inclusion criteria refused to participate. In all, 59 patients were enrolled - 36 males and 23 females. Fifteen had IDDM, 34 had NIDDM and were being treated by diet and oral hypoglycaemic agents, and 10 had NIDDM treated with insulin. Their mean age was $59.1 \pm 7.6$ years $(41-70)$ and the mean known duration of the disease was $16.8 \pm 12.5$ years (1-46). Apart from diabetes, most of them had associated coronary risk factors: arterial hypertension according to World Health Organisation criteria $(160-95 \mathrm{~mm} \mathrm{Hg})$ or treatment with an antihypertensive drug was found in $66 \%$ of the patients (39 of 59), smoking at least 10 cigarettes daily, in $30 \%$ (18 of 59 ) and total hypercholesterolaemia (over $6.5 \mathrm{mmol} / \mathrm{l}$ ) in $37 \%$ (22 of 59). As regards the clinical diagnosis of CAD, among the 59 patients, 23 had chest pain (including typical and atypical angina) without resting ECG abnormalities, 9 had only ECG abnormalities, and 27 cumulative clinical symptoms and resting ECG abnormalities (Table 1).

Methods. Cardiac evaluation was performed in the Department of Cardiology at Bichat Hospital. On separate days, patients underwent 48-h ambulatory ECG monitoring, bicycle exercise ECG and intravenous dipyridamole thallium 201 myocardial scintigraphy. Whatever the results of the non-invasive tests, coronary angiography was performed on the last day of the evaluation.
Table 1. Clinical and electrocardiographic characteristics for the diagnosis of CAD in the 59 diabetic patients

\begin{tabular}{lll}
\hline & Negative ECG & Positive ECG \\
\hline No symptoms & - & 9 \\
Symptoms & 23 & 27 \\
\hline
\end{tabular}

Among the 59 patients, 23 had chest pain (including typical and atypical angina) without resting ECG abnormalities, 9 had only ECG abnormalities and 27 had cumulative clinical symptoms and resting ECG abnormalities

All cardiac drugs were stopped at least $48-\mathrm{h}$ before the noninvasive tests. In particular, beta-blockers were progressively reduced and discontinued 5 days before the exercise ECG testing. All patients underwent 48 -h ambulatory ECG monitoring before being hospitalised. Pre-gelled electrodes were recorded to two anterior leads, CM2 and CM5. Two-channel recordings were obtained on magnetic tape (Ela Medical, Plessis Robinson, France). Recordings were analysed by the Elatec system (Ela Medical). A test was considered positive if there was an ST depression equal to or greater than $1 \mathrm{~mm}$ which was horizontal or downsloping and persisted for at least $0.08 \mathrm{~s}$ after the $J$ point, during a period of at least $1 \mathrm{~min}$.

Exercise electrocardiography. a maximal exercise test was performed on an electrically braked bicycle ergometer, starting at a workload of 30 Watts, with increments of 30 Watts every $3 \mathrm{~min}$. Blood pressure and a 12 -lead ECG were recorded before and during each stage of this test. A test was considered positive if there was an ST depression equal to or greater than $1 \mathrm{~mm}$ which was horizontal or downsloping and persisted for at least $0.08 \mathrm{~s}$ after the $\mathrm{J}$ point. It was considered negative when the heart rate reached the maximal predicted exercise heart rate without significant ST segment change. No attempt was made to correct the ST depression for resting abnormalities of repolarisation such as left ventricular hypertrophy.

Dipyridamole thallium 201 myocardial tomo-scintigraphy: dipyridamole was infused intravenously at a rate of $0.56 \mathrm{mg} / \mathrm{kg}$ body weight for $4 \mathrm{~min}$, and $3 \mathrm{~min}$ after the end of infusion, thallium $201(1.5 \mathrm{MBq} / \mathrm{kg}$ body weight) was injected. Early thallium imaging was started $5 \mathrm{~min}$ after injection, and delayed imaging took place $4 \mathrm{~h}$ later. Data were acquired with a rotating gamma camera equipped with a low-energy all-purpose collimator. No attenuation correction was performed. Each reconstructed slice was $10-\mathrm{mm}$ thick. Five regions of the left ventricle were defined: anterior, septal, apical, inferior and posterolateral; thallium uptake was graded by a 4-point score. The dipyridamole testing was considered positive for diagnosis of CAD if the thallium scan exhibited fixed or transient defects. For readings of the myocardial scintigraphy the agreement between the two observers was $95 \%$ and a consensus was obtained in case of discrepancy.

Coronary angiography: left heart catheterization was performed percutaneously through the right femoral artery. Selective coronary angiography using a size $6 \mathrm{~F}$ catheter was performed in multiple incidences. A quantitative method using electronic calipers (Brown and Sharpe Co, North Kingston, R. I., USA) interfaced with a computer (Hewlett-Packard Vectra ES/12) was used to measure stenosis in one projection. A narrowing in the cross-sectional area of $70 \%$ or greater, for one of the three major epicardial coronary arteries, or of $50 \%$ or more for the left main artery was considered haemodynamically significant. The results of each test were interpreted by two independent observers who were unaware of the clinical 
presentation and of the results of the other tests. CAD was diagnosed when coronary angiography revealed one or more significant coronary stenoses.

Glycated haemoglobin was determined by high performance liquid chromatography, with a normal value of less than $6 \%$. Total cholesterol and triglycerides were determined by enzymatic methods after an overnight fast.

\section{Statistical analysis}

Data are expressed as means \pm SD. Sensitivity was defined as (true positive/true positive + false negative) $\times 100$, and specificity was defined as (true negative/true negative + false positive) $\times 100$; the predictive value of a positive test was defined as (true positive/(true positive + false positive) $) \times 100$, and the predictive value of a negative test as (true negative/(true negative + false negative) ) $\times 100$.

\section{Results}

Angiographic findings. Of the 59 patients studied, 20 $(34 \%)$ exhibited significant coronary stenosis or stenoses as defined above, and constituted group A. The remaining 39 patients constituted group $B$, and included 29 patients with angiographically normal coronary arteries and 10 with non-significant coronary stenoses.

In group $\mathrm{A}$, the anatomical distribution of the coronary stenoses was as follows: 9 of 20 patients $(45 \%)$ had triple-vessel disease, 7 of $20(35 \%)$ double-vessel disease and 4 of $20(20 \%)$ single-vessel disease. Two of the 20 patients had significant stenosis on the left main coronary artery. The left anterior descending artery was reduced in 15 of 20 patients, the left circumflex artery, in 13 of 20 patients and the right coronary artery in 13 of 20 patients.

Clinical characteristics of the patients in groups A and B are summarized in Table 2. Group A included a majority of males.

\section{Non-invasive diagnosis of coronary artery disease}

We tested the efficacy of the three non-invasive tests for diagnosis of CAD in the 59 patients studied (Table 3). Forty-eight-hour ambulatory ECG monitoring was positive in ten patients, five in group $\mathrm{A}$ and five in group B. Sensitivity was low, at $25 \%$, with a specificity of $88 \%$. The positive and negative predictive values calculated were 50 and $69 \%$, respectively. Exercise testing was positive in 24 patients, 15 in group A, and 9 in group B. Sensitivity and specificity were calculated as 75 and $77 \%$, respectively with positive and negative predictive values of 63 and $86 \%$. Dipyridamole thallium 201 myocardial scintigraphy was positive in 21 patients displaying fixed or transient defects, 16 in group $\mathrm{A}$, and 5 in group B. Sensitivity and specificity were respective-
Table 2. Main clinical and biological characteristic of diabetic patients in group $\mathrm{A}$, with significant coronary lesions, and of those in group B, with non-significant coronary lesions or normal angiograms

\begin{tabular}{lcc}
\hline & Group A & Group B \\
\hline Sex (male, female) & $17 / 3$ & $19 / 20$ \\
IDDM $(n)$ & 7 & 8 \\
NIDDM $(n)$ & 13 & 31 \\
Age (years) & $57.5 \pm 8.1$ & $60.0 \pm 7.2$ \\
Known duration & & \\
of diabetes (years) & $21.1 \pm 13.5$ & $14.9 \pm 11.7$ \\
Body mass index $\left(\mathrm{kg} / \mathrm{m}^{2}\right)$ & $27.2 \pm 3.3$ & $28.0 \pm 4.4$ \\
HbA $_{\text {1c }}(\%)$ & $8.5 \pm 1.4$ & $8.2 \pm 1.8$ \\
Total cholesterol $(\mathrm{mmol} / \mathrm{l})$ & $6.4 \pm 1.4$ & $6.1 \pm 1.6$ \\
HDL cholesterol $(\mathrm{mmol} / 1)$ & $1.21 \pm 0.4$ & $1.15 \pm 0.4$ \\
Triglycerides $(\mathrm{mmol} / \mathrm{l})$ & $2.5 \pm 2.8$ & $1.7 \pm 1.1$ \\
Hypertension $(n)$ & 14 & 25 \\
Smoking $(n)$ & 8 & 10 \\
\hline
\end{tabular}

Table 3. Number of positive results for the three non-invasive tests in group A, patients with significant coronary lesions, and group B, patients with non-significant coronary lesions or normal angiograms. Accuracy of the three tests

\begin{tabular}{lccc}
\hline$n=59$ & $\begin{array}{l}\text { Positive 48-h } \\
\text { ambulatory } \\
\text { ECG }\end{array}$ & $\begin{array}{l}\text { Positive } \\
\text { maximal } \\
\text { exercise } \\
\text { ECG }\end{array}$ & $\begin{array}{l}\text { Positive } \\
\text { dipyridamole } \\
\text { myocardial } \\
\text { scintigraphy }\end{array}$ \\
\hline Group A, $n=20$ & 5 & 15 & 16 \\
Group B, $n=39$ & 5 & 9 & 5 \\
Sensitivity \% & 25 & 75 & 80 \\
$\begin{array}{l}\text { Specificity \% } \\
\text { Positive } \\
\text { predictive value \% }\end{array}$ & 88 & 77 & 87 \\
$\begin{array}{l}\text { Negative } \\
\text { predictive value \% }\end{array}$ & 69 & 63 & 76 \\
\hline
\end{tabular}

ly, 80 and $87 \%$, with positive and negative predictive values of 76 and $89 \%$, respectively. The four patients in group A with a negative thallium scan comprised one man with a significant stenosis on the left main coronary artery, a woman with a proximal stenosis on the left anterior descending artery, another woman with triple-vessel stenosis, and a man with a distal stenosis on a left marginal artery. All except the latter patient had positive bicycle exercise testing. Myocardial scintigraphy was positive in five of the patients in group B. In these patients, the thallium scan only showed fixed defects which were always located in the same limited postero-inferior region.

We also tested the accuracy of the three non-invasive tests according to the clinical presentation. Thus, we defined a group $\mathrm{C}(n=24)$ constituted of patients with typical angina pectoris and a group D 
Table 4. Accuracy of the three non-invasive tests according to clinical presentation. Patients with typical angina: group C, patients without symptoms or with atypical angina: group D

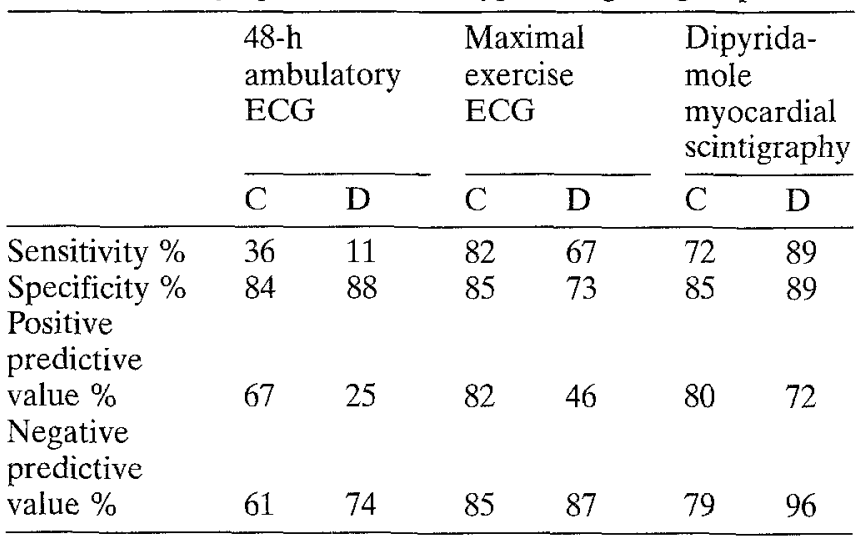

Group C, $(n=24)$ Patients with typical angina

Group D, $(n=35)$ Patients without symptoms or with atypical angina

$(n=35)$ including patients without symptoms or with atypical angina. Prevalence of CAD was higher in group C: 11 of 24, compared to group D 9 of 35 . The results are summarized in Table 4.

\section{Discussion}

In this selected diabetic population, 20 patients out of $59(34 \%)$ were found to have haemodynamically significant coronary stenosis or stenoses, 10 had a nonsignificant atherosclerotic process and 29 had angiographically normal coronary arteries. For detection of CAD, 48-h ambulatory ECG monitoring displayed low sensitivity but good specificity. Maximal exercise ECG testing had good sensitivity and specificity, and dipyridamole thallium myocardial scintigraphy displayed the best sensitivity and specificity. As the aim of this study was to determine the accuracy of three non-invasive tests, diagnosis of CAD was only made for patients with significant coronary stenosis at angiography. The prevalence of CAD is not surprising, since this population had a mean age of nearly 60 years and a mean known duration of diabetes of 15 years, and in addition to diabetes, most of the patients presented with one or more additional cardiovascular risk factors. In most of the patients of group A, coronary angiography revealed double and triple-vessel stenoses ( $80 \%$ ).

The results reported for the extent and severity of coronary lesions in diabetic patients have been conflicting. Thus, Verska and Walker [15] detected no significant difference in the extent of coronary lesions when comparing diabetic and non-diabetic patients. On the contrary, Dortimer et al. [16] demonstrated that the coronary disease was significantly more severe in diabetic patients. Valsania et al. [17] also found more diffuse atherosclerotic coronary lesions in young IDDM patients. Morris et al. [18] who studied diabetic patients before and after coronary bypass surgery found that a larger percentage of diabetic than non-diabetic patients had triple-vessel disease and received more coronary artery by-pass grafts.

In the present study, ambulatory ECG monitoring gave disappointing results, with a low sensitivity of $25 \%$. This contrasts with the results of Stern et al. [19] who reported $80 \%$ sensitivity in patients with CAD. Our results are surprising, as silent myocardial ischaemia has been reported to be frequent in diabetic patients, and we expected that the sensitivity of the test would be improved by the prolonged use of 48-h ECG monitoring and an ambulatory out-patient utilization. However, the specificity of the method was good.

As regards bicycle exercise ECG, its sensitivity, specificity and negative predictive value in the present study were satisfactory, at 75,77 and $86 \%$, respectively. Most of the patients $(92 \%)$ performed a maximal exercise test. This was unexpected for diabetic patients and may have been due to the exclusion of patients with neuropathy or severe nephropathy, and to the discontinuation of beta-blockers at least 5 days prior to exercise. Our results are in keeping with those previously reported for non-diabetic patients with CAD, i.e. 56-81 and 78-100\%, respectively for sensitivity and specificity [20-21]. The $75 \%$ sensitivity found in our study may be due to the high prevalence of double and triple-vessel disease found in this cohort, which is in agreement with the data reported by Goldschlager et al. [22]. The positive predictive value of bicycle exercise ECG was $63 \%$, a percentage which according to the Bayes' theorem [23] may have been due to the prevalence of CAD in this population. This result is in agreement with the results previously reported in asymptomatic diabetic patients $[9,11,24]$. The negative predictive value of $86 \%$ strongly supports the use of the ECG exercise test as the first step in the clinical investigation of diabetic patients, because a negative maximal exercise test is very likely to exclude the diagnosis of CAD in such a population.

Dipyridamole thallium myocardial scintigraphy, which is an excellent alternative to exercise myocardial scintigraphy [25], displayed, in the present study, the best sensitivity and specificity, with values of 80 and $87 \%$, respectively. These data are in keeping with those reported for patients with CAD [26-27]. Exercise myocardial scintigraphy has been used to evaluate CAD in several series of asymptomatic diabetic patients $[8,24,28-31]$. In most of these studies, a good predictive value for the diagnosis of future coronary events was reported, but none of them included coronary angiography. However, for the exercise thallium myocardial scintigraphy, Koistinen et al. [24] reported a low and disappointing positive predictive value in asymptomatic diabetic patients. With dipyridamole thallium myocardial scintigraphy, Nes- 
to et al. [32] reported a high prevalence (57\%) of thallium defects in diabetic patients with peripheral vascular disease, but they also did not include systematic coronary angiography. Boudreau et al. [13] who studied diabetic patients with end-stage renal failure, reported sensitivity, specificity and accuracy of about $85 \%$ for dipyridamole thallium myocardial scintigraphy, the prevalence of $\mathrm{CAD}$ in these patients being $53 \%$. Myocardial thallium scintigraphy may given false-positive results in patients with valvular heart disease, or with left bundle branch block, who were excluded from our study. It has been reported that false positive results are usually related to fixed defects in the postero-inferior segment [33]. These defects are due to an excessive splanchnic uptake of thallium 201 after dipyridamole infusion, which may interfere with assessment of perfusion in the inferior wall. In the present study, the dipyridamole thallium scan failed to identify three patients with severe CAD: one had stenosis on the left main coronary artery, and the two others, triple-vessel stenoses. In the presence of a coronary stenosis, dipyridamole-induced vasodilation results in diminished uptake of intravenously administered thallium 201 compared with the larger uptake and faster radionuclide clearance in normally perfused mycardium. The reduced uptake produces an initial thallium defect in stenosed areas compared to normally perfused regions. This explains why in patients with triple-vessel disease, false negative results were reported for thallium scintigraphy, which is a comparative method [34]. However, in our three patients, CAD was identified by positive exercise ECG testing.

Few patients exhibited normal coronary angiography but severe abnormalities were present in at least one of the three non-invasive tests. In such patients, myocardial ischaemia in relation to diabetic microangiopathy cannot be excluded.

When we tested accuracy of the three non-invasive tests according to the clinical presentation (typical angina or atypical angina), we defined two subgroups $\mathrm{C}$ and $\mathrm{D}$ with different prevalence in CAD. In the patients of group $C$ with typical angina and the higher prevalence for CAD, exercise ECG testing was the most powerful test and can be sufficient to affirm or to exclude CAD. On the other hand, in patients with atypical clinical presentation, thallium scintigraphy was an excellent alternative with in particular a very satisfactory negative predictive value.

The conditions of the present study involve some limitations: the middle-aged diabetic patients included were recruited from a tertiary diabetic referral centre to which the most severe cases of diabetes are supposed to be referred and indeed most of the patients in this study, exhibited apart from diabetes one or more additional cardiovascular risk factors. Consequently, the accuracy of the three non-invasive tests used may not apply to the diabetic population in gen- eral. The patients in our series had clinical symptoms or resting ECG abnormalities or both, and we did not explore asymptomatic patients without ECG abnormalities. Nevertheless, in a previous study [11] in which only asymptomatic diabetic patients with normal resting ECG were included, we found good predictive positive values for the ECG exercise test and myocardial thallium scintigraphy. Finally, the present study exclusively concerned diagnosis of CAD on the basis of existing haemodynamically significant coronary stenosis, and did not concern the diagnosis of myocardial ischaemia per se, the prognosis for the coronary stenoses, and the implications for treatment.

In conclusion, in this selected diabetic population, dipyridamole thallium myocardial scintigraphy was the most powerful non-invasive test for the detection of significant $\mathrm{CAD}$, but is expensive and only available in certain institutions. The maximal bicycle exercise ECG test, without any cardiological treatment, is cheaper and more widely available, and provides satisfactory sensitivity, specificity and negative predictive values. This test should be used as a first-line examination for those diabetic patients at high risk of $\mathrm{CAD}$, and should be repeated in the routine care of this population. Dipyridamole myocardial scintigraphy may provide an alternative solution for patients with atypical clinical presentation, or who cannot perform a maximal exercise, meanwhile Holter monitoring is virtually useless for non-invasive detection of CAD.

\section{References}

1. Kannel WB, Mc Gee DL (1979) Diabetes and cardiovascular risk factors. The Framingham Study. Circulation 59: 813

2. Jarrett RJ, McCartney P, Keen H (1982) The Bedford Survey - Ten year mortality rates in newly diagnosed diabetics, borderline diabetics and normoglycaemic controls and risk indices for coronary heart disease in borderline diabetics. Diabetologia 22: 79-84

3. Krolewski AS, Warram JH, Rand LI, Kahn CR (1987) Epidemiologic approach to the etiology of type 1 diabetes mellitus and its complications. N Engl J Med 317: 13901398

4. Stamler J, Vaccaro O, Neaton JD, Wentworth D (1993) For the Multiple Risk Factor Intervention Trial Research Group. Diabetes, other risk factors and 12 year cardiovascular mortality for men screened in the multiple risk factor intervention trial. Diabetes Care 16: 434-444

5. Bradley RF, Schonfeld A (1962) Diminished pain in diabetic patients with acute myocardial infarction. Geriatrics 17 : 322-326

6. Nesto RW, Phillips RT (1986) Asymptomatic myocardial ischemia in diabetic patients. Am J Medicine 80 [Supp 4c]: 40-47

7. Scheidt-Nave C, Barrett-Connor E, Wingard DL (1990) Resting electrocardiographic abnormalities suggestive of asymptomatic ischaemic heart disease associated with non-insulin-dependent diabetes mellitus in a defined population. Circulation 81: 899-906 
8. Langer A, Freeman MR, Josse RG, Steiner G, Armstrong PW (1991) Detection of silent myocardial ischemia in diabetes mellitus. Am J Cardiol 67: 1073-1078

9. Naka M, Hiramatsu K, Aizawa T et al. (1992) Silent myocardial ischemia in patients with non insulin-dependent diabetes mellitus as judged by treadmill exercise testing and coronary angiography. Am Heart J 123: 46-53

10. Smith JW, Marcus FI, Serokman R (1984) Prognosis of patients with diabetes mellitus after acute myocardial infarction. Am J Cardiol 54: 718-721

11. Paillole C, Passa Ph, Paycha F et al. (1992) Non-invasive identification of severe coronary artery disease in patients with long-standing diabetes mellitus. Eur J Med 1: 464-468

12. Weiner DA, Ryan TJ, Parsons L et al. (1991) Significance of silent myocardial ischemia during exercise testing in patients with diabetes mellitus: a report from the coronary artery surgery study (CASS) registry. Am J Cardiol 68: 729734

13. Boudreau RJ, Strony JT, Ducret RP et al. (1990) Perfusion thallium imaging of type I diabetes patients with end-stage renal disease: comparison of oral and intravenous dipyridamole administration. Radiology 175: 103-105

14. Braunwald E (1992) Examination of the patient. In: Braunwald $E$ (ed) Heart disease, a text book of cardiovascular medicine, Vol 1 W.B.Saunders Philadelphia London, pp $1-12$

15. Verska JJ, Walker WJ (1975) Aortocoronary bypass in diabetic patients. Am J Cardiol 35: 774-777

16. Dortimer AC, Shenoy PN, Shiroff RA et al. (1978) Diffuse coronary artery disease in diabetic patients. Fact or fiction? Circulation 57: 133-136

17. Valsania P, Zarich SW, Kowalchuk GJ et al. (1991) Severity of coronary artery disease in young patients with insulindependent diabetes mellitus. Am Heart J 122: 695-700

18. Morris JJ, Smith LR, Jones RH et al. (1991) Influence of diabetes and mammary artery surgery grafting on survival after coronary bypass. Circulation 84 [Suppl III]: 275-284

19. Stern S, Tzivoni D, Stern Z (1975) Diagnosis accuracy of ambulatory ECG monitoring in ischaemic heart disease. Circulation 52: 1045-1049

20. Chaitman BR, Hanson JS (1981) Comparative sensitivity and specificity of exercise electrocardiographic lead systems. Am J Cardiol 47: 1335-1349

21. Chaitman BR (1986) The changing role of exercise electrocardiogram as a diagnosis and prognosis test for chronic ischemic heart disease. J Am Coll Cardiol 8: 1195-1210
22. Goldschlager N, Selzer A, Cohn K (1976) Treadmill stress tests as indicators of presence and severity of coronary artery disease. Ann Int Med 85: 277-786

23. Diamond GA (1986) Reverend Bayes' silent majority. An alternative factor affecting sensitivity and specificity of exercise electrocardiography. Am J Cardiol 57: 1175-1179

24. Koistinen MJ, Huikuri HV, Pirttiaho H, Linnaluoto MK, Takkunen JT (1990) Evaluation of exercise electrocardiography and thallium tomographic imaging in detecting asymptomatic coronary artery disease in diabetic patients. Br Heart J 63: 7-11

25. Beller GA (1989) Dipyridamole thallium-201 scintigraphy: an excellent alternative to exercise scintigraphy. J Am Coll Cardiol 14: 1642-1644

26. Beller GA (1991) Pharmacologic stress imaging. JAMA 265: 633-638

27. Iskandrian AS, Heo J, Askenase A, Segal B, Auerbach N (1988) Dipyridamole cardiac imaging. Am Heart J 114: 432-443

28. Abenavoli T, Rubler S, Fisher VJ et al. (1981) Exercise testing with myocardial scintigraphy in asymptomatic diabetic males. Circulation 63: 54-64

29. Rubler S, Fisher VJ (1985) The significance of repeated exercise testing with thallium-201 scanning in asymptomatic diabetic males. Clin Cardiol 8: 621-628

30. Rubler S, Gerber D, Reitano J, Chokshi V, Fisher VJ (1987) Predictive value of clinical and exercise variables for detection of coronary artery disease in men with diabetes mellitus. Am J Cardiol 59: 1310-1313

31. Felsher J, Meissner MD, Hakki AH et al. (1987) Exercise thallium imaging in patients with diabetes mellitus. Arch Intern Med 147: 313-317

32. Nesto RW, Watson FS, Kowalchuk GJ et al. (1990) Silent myocardial ischemia and infarction in diabetics with peripheral vascular disease: assessment by dipyridamole thallium 201 scintigraphy. Am Heart J 120: 1073-1077

33. Iskandrian AS, Heo J (1990) Appraisal of false positive results in nuclear cardiac imaging. Am Heart J 119: 708-709

34. Maddahi J, Abdulla G, Garcia EV, Swan HJC, Berman DS (1986) Non-invasive identification of left main and triple vessel coronary artery disease: improved accuracy using quantitative analysis of regional myocardial stress distribution and washout of thallium-201. J Am Coll Cardiol 7: 5360 